\title{
Accelerated Access to Medicinal Products
}

\begin{abstract}
Kaat Van Delm*
Multiple procedures and projects accelerating patient access to medicinal products have been rolled out in the EU. This paper provides an overview of the procedures currently in place at EU level aiming to accelerate the centralised marketing authorisation procedure for new medicinal products. Specifically, accelerated assessment, parallel consultations of EMA and HTA bodies, the PRIME scheme, SME support, conditional marketing authorisation, exceptional circumstances, CHMP opinions on compassionate use and adaptive pathways are discussed. The coherence of the procedures and implications on applicants' legal certainty is analysed, and the procedures are compared with their most similar US counterparts. Subsequently, the relevance of such procedures for the current Covid-19 crisis is highlighted. It is demonstrated that many of the existing EU procedures are intertwined and many of the EU procedures have a resembling counterpart in the US. Even though for access to most EU procedures the applicant should demonstrate the presence of an 'unmet need', this concept is not defined homogenously for all procedures, reducing legal certainty. In conclusion, the overview of the procedures in place at EU level demonstrates that the system is overly complicated.
\end{abstract}

\section{Introduction}

Both in the European Union (EU) and in the United States of America (US) multiple procedures and projects have been rolled out with a view to accelerate patient access to medicinal products. The quantity of procedures in place in itself already is a challenge for marketing authorisation applicants. The current COVID-19 pandemic and the related race for a vaccine highlights the relevance of accelerated procedures for medicinal product authorisation even more. This paper provides an overview of the procedures currently in place at EU level accelerating access to new medicinal products, analysing the coherence of the procedures in place with a focus on the implications thereof on the applicants' legal certainty. In addition, the procedures are compared with their most similar US counterparts in order to highlight the similarities and differences in approaches in the EU and the US. Finally, the potential for COVID-19 vaccines is summarised.

This article is limited to new medicinal products for human use. In addition, the main focus of this paper is on types of applications accelerating access to marketing authorisation, and not on specific types of medicinal products whereby the nature of the product itself accelerates access as such. Even though important additional procedures are indeed in place expediting access to specific types of medicinal products such as orphan medicinal products, ATMP products or medicinal products for early paediatric interaction, these are out of scope. Further, the paper focusses on EU procedures accelerating the centralised marketing authorisation procedure. Mechanisms in place to accelerate marketing authorisation at member state level are not included. This focus eases comparison with the US procedures, which all fall under the central federal authority of the US Food \& Drug Administration (FDA). Finally, the paper is focussed on the position of the marketing authorisation applicants, and not on the implications of the accelerated procedures on the position of patients (for example safety implications).

\section{Procedures Granting Accelerated Access}

Throughout the years, many different procedures and projects have been created at EU level aiming to

DOI: $10.21552 / \mathrm{eplr} / 2020 / 4 / 4$

* Kaat Van Delm, PhD researcher at KULeuven, Leuven Institute for Healthcare Policy (LIHP/LIGB). For Correspondence:

$<$ kaatjozefn.vandelm@kuleuven.be> 
accelerate patient access to medicinal products. This chapter provides an overview of the procedures currently available for acceleration of the EU centralised marketing authorisation procedure. The various procedures are discussed in an order which demonstrates how they are related. For each procedure, it is described how the mechanism facilitates access to medicinal products for patients, on what legal basis the procedure is based and which are the conditions for being allowed to access the procedure. In addition, a comparison is made with the most similar US counterpart. Pairing such EU and US procedures is artificial, since no US procedure is an exact copy of an EU procedure and since many procedures carry similar characteristics, blurring the delimitation of the procedures both at EU and US level. However this approach displays the overall structure of both legal systems most clearly.

\section{Accelerated Assessment}

\begin{tabular}{|l|l|}
\hline Name tool/procedure & Accelerated assessment \\
\hline Legal basis & $\begin{array}{l}\text { Article 14(9) of Regulation } \\
726 / 2004^{\mathrm{a}}\end{array}$ \\
\hline Date of introduction & 2005 \\
\hline $\begin{array}{l}\text { Conditions for use/access } \\
\text { (1) Unmet need? } \\
\text { (2) Other }\end{array}$ & $\begin{array}{l}\text { (1) De facto yes, unmet } \\
\text { medical need } \\
\text { (2) Of major public health } \\
\text { interest }\end{array}$ \\
\hline Characteristics licence & Permanent or conditional \\
\hline Institution concerned & EMA \\
\hline
\end{tabular}

a Regulation 726/2004 of the European Parliament and of the Council of 31 March 2004 laying down Community procedures for the authorisation and supervision of medicinal products for

1 Regulation 726/2004, art 14(9) §2.

2 EMA, 25 February 2016, 'Guideline on the scientific application and the practical arrangements necessary to implement the procedure for accelerated assessment pursuant to Article 14(9) of Regulation (EC) No 726/2004' nr. EMA/CHMP/671361/2015 Rev. 1 (Accelerated Assessment Guideline).

3 ibid 4

4 ibid human and veterinary use and establishing a European Medicines Agency [2004] OJ L 136/1 (Regulation 726/2004).

The procedure for accelerated assessment was established in 2005 . The aim of the accelerated assessment procedure is to reduce the term within which the Committee for Medicinal Products for Human Use (CHMP) is required to issue an opinion if a valid marketing-authorisation application for a medicinal product for human use has been submitted: if successful, the term is reduced from 210 to 150 days. ${ }^{1}$

\section{a. Legal Basis}

Article 14(9) of Regulation 726/2004 specifies that an application for marketing authorisation regarding medicinal products for human use 'of major interest from the point of view of public health and in particular from the viewpoint of therapeutic innovation, the applicant may request an accelerated assessment procedure' (emphasis added). The specific rules for this procedure are set out in guidelines on the implementation of the procedure for accelerated assessment. $^{2}$

\section{b. Conditions}

In 2006, EMA issued the Accelerated Assessment Guideline, which was updated in 2016. In this Accelerated Assessment Guideline, one would expect to find a clear explanation of what constitutes a medicinal product of major interest from the point of view of public health. On the contrary however, the Accelerated Assessment Guideline states explicitly that no single definition is available and that this criterion is 'assessed by CHMP on a case by case basis'. ${ }^{3}$ It is up to the applicant to prove this criterion is fulfilled. The only guidance provided is that addressing 'unmet medical needs for maintaining and improving the health of the Community' could be a justification, eg by introducing new or improving existing methods or therapies. ${ }^{4}$ The guideline therefore suggests the applicant to include the following topics in its justification: (1) the unmet medical need to be addressed and the currently available methods or therapies; (2) in how far the medicinal product is expected to fulfil such need; and (3) the strength of the applicant's evidence supporting its justification that a major interest from the point of view of public health is addressed. The guideline is formulated in a very conditional way, probably in order to leave room for cre- 
ativity of the applicant, though de facto building all guidance on the concept of unmet medical need.

\section{c. US Priority Review}

If granted priority review designation, the FDA takes action with regard to a marketing authorisation application within 6 months, instead of 10 months under standard review. ${ }^{5}$ In order to be eligible for priority review, a medicinal product must (1) treat a serious condition and (2) if approved, the medicinal product should provide a significant improvement in safety or effectiveness. ${ }^{6}$ Examples of such improvements are 'evidence of increased effectiveness in treatment, prevention or diagnosis of a condition [or], elimination of substantial reduction of a treatment-limiting adverse reaction'.7 Such evidence can be based on clinical trials, but also on other scientifically valid information. Other specific statutory provisions grant priority review designation to specific types of applications (for example targeting the treatment of certain tropical diseases), and therefore are less comparable to the EU accelerated assessment procedure. The aim of the EU accelerated assessment and US priority procedure is clearly similar: a reduction of the review time of the competent authority. Also the qualification criteria are similar, introducing a threshold regarding the societal interest and how the treatment will be beneficial to the outcome.

\section{Scientific Advice: Parallel Consultations EMA and HTA Bodies}

In its current form, the parallel consultations of EMA and the European Network for Health Technology Assessment (EUnetHTA) ${ }^{8}$ exists since 2017. Multiple other scientific advice assistance procedures exist, though this article focusses on the simultaneous procedures, increasing the applicant's efficiency while developing the medicinal product concerned, and therefore accelerating access to such medicinal product. The aim of this scientific advice procedure is for applicants to receive simultaneous feedback from both EMA and HTA bodies on the applicant's evidence-generation plans in order to ensure that the evidence generated is a sufficient basis for both marketing authorisation and reimbursement decisionmaking. The parallel consultations may be in written form only or face to face, as decided by EUnetH-
TA unilaterally, depending on a.o. the following criteria: 'PRIME products; ${ }^{9}$ complexity of the development; need for an in-depth discussion with the applicant about the development plan [...]; Major issues with the development plan [...].'. ${ }^{\prime 0}$ The procedure in writing takes approximately 2.5 months, while the face to face format takes around 3.5 months in total.

\begin{tabular}{|l|l|}
\hline Name tool/procedure & $\begin{array}{l}\text { Parallel consultations from } \\
\text { regulators and HTA bodies }\end{array}$ \\
\hline Legal basis & N/A \\
\hline Date of introduction & 2017 \\
\hline $\begin{array}{l}\text { Conditions for use/access } \\
(\mathbf{1}) \text { Unmet need? } \\
(\mathbf{2}) \text { Other }\end{array}$ & $\begin{array}{l}(\mathbf{1}) \text { Yes, no treatment or un- } \\
\text { satisfactory treatment avail- } \\
\text { able } \\
(\mathbf{2}) \text { new mode of action; tar- } \\
\text { geting life-threatening or } \\
\text { chronically debilitating dis- } \\
\text { ease }\end{array}$ \\
\hline $\begin{array}{l}\text { Characteristics licence } \\
\text { Institution concerned }\end{array}$ & Permanent or Conditional \\
\hline
\end{tabular}

\section{a. Legal Basis}

As the feedback on evidence generation from EMA and EUnetHTA is not legally binding, the basis of this procedure is not reflected in a specific regulation or directive. The details and rationale of the proce-

5 Center for Drug Evaluation and Research (CDER), 25 June 2013 , 'Review Designation Policy: Priority (P) and Standard (S)' No. MAPP 6020.3 Rev.2, <https://www.fda.gov/media/72723/ download>, accessed on 12 October 2020; FDA, 'Priority Review', <https://www.fda.gov/patients/fast-track-breakthrough -therapy-accelerated-approval-priority-review/priority-review> , accessed on 11 October 2020.

6 FDA, May 2014, 'Guidance for Industry - Expedited Programs for Serious Conditions - Drugs and Biologics' OMB Control No. 0910-0765 (U.S. Expedited Programs Guidance), 7 and 24.

7 ibid $24-25$.

8 EUnetHTA is an organisation created in order to 'support collaboration between European HTA organisation that brings added value to healthcare systems at the European, national, and regional level.' (EUnetHTA, 'Vision, Mission, and Values', <https:// eunethta.eu/about-eunethta/mission-vision-and-values/> , accessed on 8 October 2020). They do so via 'the facilitation of efficient HTA resource use; The creation of a sustainable system of HTA knowledge sharing; The promotion of good practice in HTA methods and processes.' (EUnetHTA, 'About EUnetHTA', <https:// eunethta.eu/about-eunethta/> , accessed on 8 October 2020).

9 For more information on PRIME: see chapter II.3.

10 Parallel Consultation Guidance, 11. 
dure are set out in the guidance on parallel consultation, ${ }^{11}$ issued together by EMA and EUnetHTA.

\section{b. Conditions}

The amount of products selected for parallel consultations is limited. Where an applicant intends to apply for participation in parallel consultations, the applicant should demonstrate in a letter of intent that the product aims 'to bring added benefit to patients ie by: (1) a new mode of action for the indication; AND (2) targeting a life-threatening or chronically debilitating disease; AND (3) responding to unmet need (no treatment or only unsatisfactory treatment available) $)^{\prime 2}$ No further clarifications regarding these criteria is provided. In addition, the guidance stresses that it aims to include a diverse selection of medicinal products in the parallel consultations. The procedure is open to applicants for any medicinal product for human use, irrespective of whether the medicinal product is eligible for the centralised procedure, and irrespective of the advancement of the product lifecycle. ${ }^{13}$

\section{c. EU/US Parallel Scientific Advice (PSA)}

Contrary to the other US procedures discussed in this paper, PSA is an EU-US cooperation. The aim of PSA is to encourage EMA and the FDA to exchange infor-

11 Guidance EMA nr. EMA/410962/2017 Rev.3, 3 July 2020, Guidance on parallel consultation, < https://eunethta.eu/wp-content/ uploads/2020/07/Guidance-on-parallel-consultation.pdf> , accessed on 8 October 2020 (Parallel Consultation Guidance).

12 ibid 10.

13 ibid 8-9.

14 EMA and FDA, April 2017, 'General Principles EMA - FDA Parallel Scientific Advice (Human Medicinal Products') nr. EMA/309801/2017 (PSA General Principles), <https://www.ema .europa.eu/en/documents/other/general-principles-european -medicines-agency-food-drug-administration-parallel-scientific -advice_en.pdf $>$, accessed on 12 October 2020, 1.

15 PRIME Guidance, 10; FDA, 'Frequently Asked Question: Breakthrough Therapies', <https://www.fda.gov/regulatory-information/ food-and-drug-administration-safety-and-innovation-act-fdasia/ frequently-asked-questions-breakthrough-therapies>, accessed on 12 October 2020 (FDA FAQ Breakthrough Therapies).

16 PSA General Principles, 3.

17 ibid 2.

18 EMA, 4 March 2016, 'Launch of PRIME - Paving the way for promising medicines for patients' nr. EMA/89921/2016, <https:// www.ema.europa.eu/en/documents/press-release/launch-prime -paving-way-promising-medicines-patients_en.pdf>, accessed on 8 October 2020.

19 PRIME Guideline, 3.

20 PRIME Guidance, 3. mation while a new medicinal product is still in the development phase, in order to 'avoid unnecessary testing replication or unnecessary diverse testing methodologies.'. ${ }^{14}$ It is a voluntary procedure, relevant for applicants who need scientific input from both EMA and the FDA. In order to obtain PSA, an applicant should address one single request thereto to both EMA and the FDA. ${ }^{15}$ The number of PSA procedures available is limited. If accepted, the applicant will participate in joint PSA meetings with both EMA and the FDA to discuss the relevant scientific questions concerned. Each of the agencies retains its individual decision-making authority regarding the decision on the final marketing authorisation. ${ }^{16}$ Like the EU parallel consultation, this procedure too is focussed on the alignment of independent instances in order to save time, while maintaining individual decision-making power. However, while at EU level this includes a focus on reimbursement, PSA solely focusses on market access. PSA neither explicitly considers the severity of the disease as an official selection criterion, even though it is mentioned that the best candidates for PSA include important medicinal products, especially those being developed for indications lacking development guidelines'. ${ }^{17}$

\section{PRIME (Priority Medicines)}

\begin{tabular}{|l|l|}
\hline Name tool/procedure & PRIME \\
\hline Legal basis & N/A \\
\hline Date of introduction & 2016 \\
\hline $\begin{array}{l}\text { Conditions for use/access } \\
\text { (1) Unmet need? } \\
(\mathbf{2}) \text { Other }\end{array}$ & $\begin{array}{l}(\mathbf{1}) \text { De facto yes, unmet } \\
\text { medical need } \\
(\mathbf{2}) \text { of major public health } \\
\text { interest }\end{array}$ \\
\hline $\begin{array}{l}\text { Characteristics licence } \\
\text { Institution concerned }\end{array}$ & Permanent or conditional \\
\hline
\end{tabular}

The PRIME scheme was launched by the European Commission in March 2016. ${ }^{18}$ The aim of the PRIME scheme is to improve scientific and regulatory support to promising new medicines, ${ }^{19}$ with a view to improving development and accelerated assessment of such products. ${ }^{20}$ Therefore, via PRIME it is possible 
for applicants to as well (1) identify the medicinal products eligible for accelerated assessment at an earlier stage; and (2) receive enhanced regulatory and scientific support during the application process. Specifically, successful applicants to the PRIME scheme receive early appointment of a CHMP rapporteur, a specific kick-off meeting with multidisciplinary participation from the EU Network, scientific advice on key decision points for the preparation of their marketing authorisation application, coordinated support from EMA throughout the medicinal product development with regard to regulatory aspects and a confirmation of the medicinal product's potential for accelerated assessment eligibility upon marketing authorisation application. ${ }^{21}$ Where a medicinal product is accepted for the PRIME scheme, it is expected to be allowed for accelerated assessment, however this is reassessed throughout the process, and reconfirmed if all conditions remain fulfilled. ${ }^{22}$ Exclusion from the PRIME scheme does not mean one cannot apply for accelerated assessment. The outcome of the PRIME scheme application is made public by the CHMP. Specific rules apply to SMEs, as discussed below.

\section{a. Legal Basis}

The PRIME scheme is a tool which aims to support the development of medicinal products on the basis of existing legal tools, without creating further regulatory procedures. Therefore, no specific legal basis is in place, apart from the legal basis in place for the accelerated assessment procedure which intrinsically is part of PRIME. The rules in place for the PRIME scheme are described most exhaustively in two documents issued by EMA, referred to in this paper as the PRIME Guidance ${ }^{23}$ and the PRIME Guideline. ${ }^{24}$

\section{b. Conditions}

A medicinal product is only eligible for PRIME if it is 'innovative and yet to be placed on the EU market. ${ }^{25}$ Specifically, the criteria in place for eligibility for the PRIME scheme are identical to those for accelerated assessment, ie it should be demonstrated that the medicinal product is of major public health interest, in particular from the viewpoint of therapeutic innovation. The PRIME Guideline and Guidance immediately specify that as such, the medicinal product should therefore provide a solution to an unmet medical need. It is recommended to base argu- mentation in that regard as much as possible on epidemiological data about the disease concerned. ${ }^{26}$ In addition, the application for the PRIME scheme should demonstrate the potential to address the specified unmet medical need, and therefore is expected to be supported with evidence. ${ }^{27}$ The applicant should be able to demonstrate a proof of concept, and therefore it is expected that entry to the PRIME scheme is reserved for medicinal products for which exploratory studies are already available, providing clinical response and safety data in patients. ${ }^{28}$

\section{c. US Fast Track Designation}

The aim of the fast track procedure is to facilitate the development of a medicinal product and to expedite the review thereof. ${ }^{29} \mathrm{~A}$ medicinal product is eligible for this scheme if two conditions are fulfilled. First, it should be intended for the treatment of a serious or life-threatening disease or condition. This includes a new use of an approved medicinal product. ${ }^{30} \mathrm{Se}-$ cond, it has the potential to address unmet medical needs for such disease or it is qualified as a qualified infectious disease product. ${ }^{31}$ The latter concerns a fast track designation because of the type of medicinal product concerned and therefore is less relevant for comparison with the EU PRIME scheme. The US Expedited Programs Guidance stipulates that demonstration of the potential to address unmet medical need depends on the stage of development of the

21 PRIME Guideline, 6-7; PRIME Guidance, 3.

22 PRIME Guidance, 8.

23 EMA, 7 May 2018, 'European Medicines Agency Guidance for applicants seeking access to PRIME scheme' nr.

EMA/191104/2015, <https://www.ema.europa.eu/en/documents/ other/european-medicines-agency-guidance-applicants-seeking -access-prime-scheme_en.pdf> accessed on 8 October 2020 (PRIME Guidance).

24 EMA, 7 May 2018, 'Enhanced early dialogue to facilitate accelerated assessment of PRlority Medicines (PRIME)' $\mathrm{nr}$

EMA/CHMP/57760/2015, Rev. 1, <https://www.ema.europa.eu/ en/documents/regulatory-procedural-guideline/enhanced-early -dialogue-facilitate-accelerated-assessment-priority-medicines -prime_en.pdf > accessed on 8 October 2020 (PRIME Guideline).

25 ibid 4.

26 ibid Annex 1, 9.

27 ibid 5; PRIME Guidance, 4.

28 PRIME Guideline, 9-10.

29 Section 356(b)(1) Title 21 U.S. Code.

30 U.S. Expedited Programs Guidance, 9.

31 Specifically, 'an antibacterial or antifungal drug for human use intended to treat serious or life-threatening infections' (Section 355f(g) Title 21 U.S. Code). 
medicinal product. If still in an early stage, 'evidence of activity in a nonclinical model, a mechanistic rationale, or pharmacologic data ${ }^{\prime 32}$ could suffice, while in later stages clinical data should be included. Following fast track designation, an applicant has the opportunity to have frequent interactions with the FDA. The procedure can be combined with as well accelerated approval (see further) as priority review. ${ }^{33}$ Both PRIME and fast track designation are focussed on enhanced interaction with regulatory authorities in order to expedite market access. Where PRIME is built on the accelerated assessment procedure, fast track designation can be combined with priority review designation. Both can also be combined with conditional licencing of the medicinal product concerned. However, where PRIME is merely focussed on promising new medicinal products, fast track designation can also be granted to new uses of approved medicinal products. In addition, the proof to be presented in order to be eligible for PRIME is more extensive than for fast track designation. PRIME is also often compared to the US breakthrough therapy scheme, which is discussed below.

\section{SME Support}

\begin{tabular}{|l|l|}
\hline Name tool/procedure & SME support \\
\hline Legal basis & $\begin{array}{l}\text { Art. 70.2 Regulation } \\
726 / 2004 ; \text { Commission } \\
\text { Regulation 2049/2005 }\end{array}$ \\
\hline Date of introduction & 2005 \\
\hline
\end{tabular}

32 U.S. Expedited Programs Guidance, 9.

33 ibid

34 Commission Regulation 2049/2005 of the European Parliament and of the Council of 15 December 2005 laying down, pursuant to Regulation (EC) No 726/2004 of the European Parliament and of the Council, rules regarding the payment of fees to, and the receipt of administrative assistance from, the European Medicines Agency by micro, small and medium-sized enterprises [2005] OJ L 329/4 (Commission Regulation 2049/2005), recital 3.

35 ibid art. 7.

36 PRIME Guideline, 6.

37 Regulation 297/95 of the Council of 10 February 1995 on fees payable to the European Agency for the Evaluation of Medicinal Products [1995] OJ L 35/1, art 8.1.

38 Commission Regulation 2049/2005, art 7.1(b).

39 ibid art 11

\begin{tabular}{|l|l|}
\hline $\begin{array}{l}\text { Conditions for use/access } \\
\text { (1) Unmet need? } \\
\text { (2) Other }\end{array}$ & $\begin{array}{l}\text { (1) De facto yes } \\
\text { (2) SME status }\end{array}$ \\
\hline Characteristics licence & Permanent or conditional \\
\hline Institution concerned & EMA \\
\hline
\end{tabular}

In 2005, the European Commission has adopted measures in order to support micro, small and mediumsized enterprises (SMEs). Such support consists of many measures: reduction of fees for the marketing of medicinal products, deferral of payment of certain fees and additional administrative assistance. ${ }^{34}$ This chapter focusses on these SME measures directly accelerating access to SME medicinal products, specifically the SME eligibility for a specific variation of the PRIME scheme and the related reduction of fees for scientific advice. ${ }^{35}$ If eligible for the PRIME scheme, an SME is granted PRIME support in earlier stages of the development than other PRIME beneficiaries. The advantages of PRIME for SMEs include (1) the raising of awareness of regulatory requirements by providing scientific and regulatory advice on an SME's overall development plan; (2) overcoming of financial hurdles; and (3) receipt of fee reductions on scientific advice requests. ${ }^{36}$ The financial benefits for SMEs eligible for the PRIME scheme are the same as those for other SMEs outside the PRIME scheme. Specifically, in order to receive scientific advice from EMA, a fee of EUR 89000 is due by a marketing authorisation applicant for a medicinal product for human use. ${ }^{37}$ However for an organisation with SME status, a 90\% reduction is granted. ${ }^{38}$ The stakes for being recognised as SME in the framework of medicinal product development are thus high. An 'SME Office' makes sure the measures in place are accessible to SMEs, giving advice to SMEs on administrative and procedural steps for compliance with Regulation 726/2004 and providing answers to requests and applications from SMEs. ${ }^{39}$

\section{a. Legal basis}

The applicable reductions and SME Office assistance are stipulated in Commission Regulation 2049/2005. The specific variation to the PRIME scheme designed exclusively for SMEs and applicants from the academic sector is set out in the PRIME Guideline, which sets out the conditions for admission. 


\section{b. Conditions}

First, the organisation applying for SME PRIME assistance needs to fulfil the requirements and register with EMA as an SME established in the EU: Recommendation 2003/316 defines 'SME' as follows

'The category of micro, small and medium-sized enterprises (SMEs) is made up of enterprises which employ fewer than 250 persons and which have an annual turnover not exceeding EUR 50 million, and/or an annual balance sheet total not exceeding EUR 43 million. ${ }^{40}$ (emphasis added)

In addition, if the SME wishes to benefit from the advantages of the PRIME scheme, it should comply with the specific requirements set out in the PRIME Guideline. Contrary to other PRIME applicants, medicinal products of SMEs can be added to PRIME at an earlier stage of development. SMEs need to prove the medicinal product targets an unmet medical need and has the potential to remedy such unmet medical need, like other applicants. However, contrary to the other applicants, SMEs do not need to provide the same level of evidence: instead of a proof of concept, they merely need to demonstrate a proof of principle, ie a convincing scientific concept. This implies that access to the PRIME scheme is also available if only evidence based on non-clinical data or very early clinical data is available. Of course however, the 'observed effect must be sufficiently large and/or of long duration [and] compelling to outweigh the many remaining uncertainties.' ${ }^{41}$

\section{c. US Small Business Assistance}

Also in the US, specific assistance is provided to small businesses. In relation to medicinal products for human use, a small business is defined as 'an entity that has fewer than 500 employees, including employees of affiliates, and that does not have a drug product that has been approved under a human drug application and introduced or delivered for introduction into interstate commerce. ${ }^{42}$ Here too, small businesses are entitled to receive a waiver for or reduction of certain fees, such as the application fee. ${ }^{43}$ The FDA has also created the 'CDER Small Business and Industry Assistance' (CDER SBIA), an FDA department aiming to assist small pharmaceutical businesses digest the information available from the FDA, and assisting them to understand the regulation of human medicinal products. ${ }^{44}$ This service clearly bears similarities with the EU SME Office. However, contrary to the procedure in place in the EU, such measures do not amount in a specific procedure accelerating access to medicinal products from SMEs. Therefore it has to be concluded that, while in the US there definitely are supportive measures in place for SMEs, no specific accelerated procedure for SMEs exists.

\section{Conditional Marketing Authorisation}

\begin{tabular}{|l|l|}
\hline Name tool/procedure & $\begin{array}{l}\text { Conditional marketing au- } \\
\text { thorisation }\end{array}$ \\
\hline Legal basis & $\begin{array}{l}\text { Article 14-a Regulation } \\
726 / 2004 \text {; Commission } \\
\text { Regulation 507/2006 }\end{array}$ \\
\hline Date of introduction & 2006 \\
\hline $\begin{array}{l}\text { Conditions for use/access } \\
\text { (2) Other }\end{array}$ & $\begin{array}{l}\text { (1) Yes, unmet medical } \\
\text { need } \\
\text { (2) Seriously debilitating } \\
\text { diseases or life-threatening } \\
\text { diseases/used in emergency } \\
\text { situations in response to } \\
\text { public health threats/or- } \\
\text { phan medicinal products; } \\
\text { positive risk-benefit bal- } \\
\text { ance; likely provision clini- } \\
\text { cal data; benefit to public } \\
\text { health outweighs risk of in- } \\
\text { complete date }\end{array}$ \\
\hline Institution concerned & $\begin{array}{l}\text { Conditional } \\
\text { EMA }\end{array}$ \\
\hline
\end{tabular}

The conditional marketing authorisation procedure was established in 2006. The aim of the procedure is to allow market access to medicinal products for

40 Recommendation 2003/361 of the Commission of 6 May 2003 concerning the definition of micro, small and medium-sized enterprises [2003] OJ L 124/36 (Recommendation 2003/316), art 2 of Annex 1.

41 PRIME Guideline Annex 1, 10-11.

42 Section 379h(d)(3)(A) Title 21 U.S. Code.

43 Sections $379 \mathrm{~h}(\mathrm{~d})(1)(\mathrm{c})$ and (3)(B) Title 21 U.S. Code.

44 FDA, 'About CDER Small Business and Industry Assistance (SBIA)', <https://www.fda.gov/drugs/cder-small-business-industry -assistance-sbia/about-cder-small-business-and-industry -assistance-sbia>, accessed on 13 October 2020. 
which data are less complete than is normally the case, in order to address unmet medical needs of patients. ${ }^{45}$ If accepted for conditional marketing authorisation, such authorisation is only valid for one year, though on a renewable basis. ${ }^{46}$ In addition, specific follow-up obligations are imposed on the conditional authorisation holder, which may include the completion of studies to confirm a positive risk-benefit balance and the provision of specific pharmacovigilance data. ${ }^{47}$ If such follow-up obligations are fulfilled, the CHMP may at any time grant a final marketing authorisation. ${ }^{48}$ As long as a medicinal product only has conditional marketing authorisation, this should be clearly reflected to patients and healthcare professionals in the product characteristics summary and on the package leaflet. ${ }^{49}$

\section{a. Legal Basis}

Conditional marketing authorisation is embedded in article 14-a of Regulation 726/2004, which allows the European Commission to further set out the applicable rules. The detailed procedure for conditional marketing authorisation is laid down in Commission Regulation 507/2006.

\section{b. Conditions}

Three categories of medicinal products are eligible for conditional marketing authorisation of which two are

\footnotetext{
45 Commission Regulation 507/2006 of 29 March 2006 of the European Parliament and of the Council on the conditional marketing authorisation for medicinal products for human use falling within the scope of Regulation (EC) No 726/2004 [2006] OJ L 92/6 (Commission Regulation 507/2006), recital 2.

46 ibid recital 9 .

47 ibid art 5.

48 ibid art 7.

49 ibid art 8.

50 The third category concerns medicinal products designated as orphan medicinal products; Commission Regulation 507/2006 recital 10 and art 2 .

51 Directive 2001/83/EC of the European Parliament and of the Council of 6 November 2001 on the Community code relating to medicinal products for human use [2001] OJ L 311/67 (Directive $2001 / 83)$, art $1(28)$ and $1(28 a)$.

52 Commission Regulation 507/2006, recital 4 and art $4.1 \S 2$.

53 ibid art. 4

54 Regulation 726/2004, art 14-a.2.

55 FDA FAQ Breakthrough Therapies.

56 U.S. Expedited Programs Guidance, 16

57 Section 356(c) (1)(A) Title 21 U.S. Code.
}

relevant for this assessment: (1) those which aim to treat, prevent or diagnose seriously debilitating diseases or life-threatening diseases; and (2) those used in emergency situations in response to public health threats duly recognised by the WHO or the EU. ${ }^{50}$ If the application concerns such medicinal product, four additional requirements should be met. First, there should be a positive risk-benefit balance, ie the positive therapeutic effects of the medicinal product should outweigh the risks related to the use of the medicinal product. ${ }^{51}$ Second, there is a likeliness that the applicant will provide comprehensive clinical data. Inherently, this condition implies that data are merely lacking from the clinical part of the application dossier, so no pre-clinical or pharmaceutical data can be lacking. Failure to provide a complete overview of the latter data is only acceptable in emergency situations, as referred to higher. ${ }^{52}$ Third, the authorisation fulfils an unmet medical need. Fourth, the foreseen benefit to public health outweighs the inherent risk amounting from the fact that additional data are still required in order to be able to fully assess the medicinal product. ${ }^{53}$ With regard to conditional marketing authorisation, the term 'unmet medical need' is defined as 'a condition for which there exists no satisfactory method of diagnosis, prevention or treatment authorised in the Union or, even if such a method exists, in relation to which the medicinal product concerned will be of major therapeutic advantage to those affected. ${ }^{54}$ Whether this definition can be copied one-on-one to procedures not providing a definition of this term remains the question. As some of the other procedures are vigilant when using the exact term 'unmet medical need', by speaking in a conditional way or only referring to an 'unmet need', one should remain cautious when directly relying on the definition presented here.

\section{c. US Accelerated Approval}

The aim of the US accelerated approval procedure is to speed up the development and approval of a promising medicinal product. ${ }^{55} \mathrm{~A}$ medicinal product is eligible for accelerated approval if first, it is intended to treat a serious or life-threatening disease or condition. Second, the medicinal product should present a meaningful advantage over existing treatments. ${ }^{56}$ The availability or lack of alternative treatments is taken into account for such assessment. ${ }^{57}$ Third, the medicinal product must have an effect 'on a surrogate endpoint that is reasonably likely to predict clin- 
ical benefit, or on a clinical endpoint that can be measures earlier than irreversible morbidity or mortality. ${ }^{58}$ It needs to be reasonably likely to predict an effect on irreversible morbidity or mortality or other clinical benefit. ${ }^{59}$ Accelerated approval has most been used in the context of long disease courses, where it inherently takes longer to measure the effect of a medicinal product. ${ }^{60}$ In the context of accelerated approval, post-authorisation requirements are generally imposed on the applicant, specifically the conduct of post-approval studies in order to verify the predicted effect on irreversible morbidity, mortality or another clinical benefit, and the submission of copies of the promotional materials related to the product during a certain period of time. ${ }^{61}$ If such postapproval studies provide satisfactory results, the FDA grants traditional approval for the medicinal product concerned. ${ }^{62}$ The procedure can be combined with fast track or breakthrough therapy designation if all conditions are met. The procedure is very similar to EU conditional marketing authorisation: both authorisations are subject to the fulfilment of further follow-up tasks and, upon fulfilment thereof, may be replaced by ordinary marketing authorisation. They both require the establishment of an unmet need and of a life-threatening or emergency situation.

\section{Exceptional Circumstances}

\begin{tabular}{|l|l|}
\hline Name tool/procedure & $\begin{array}{l}\text { Marketing authorisation } \\
\text { under exceptional circum- } \\
\text { stances }\end{array}$ \\
\hline Legal basis & $\begin{array}{l}\text { Art. 14(8) Regulation } \\
726 / 2004 ; \text { Annex I, Part II } \\
\text { Directive 2001/83 }\end{array}$ \\
\hline Date of introduction & 2004 \\
\hline $\begin{array}{l}\text { Conditions for use/access } \\
\text { (2) Other need? }\end{array}$ & $\begin{array}{l}(\mathbf{1}) \text { N/A } \\
(2) \text { Exceptional circum- } \\
\text { stances (because of which } \\
\text { comprehensive evidence } \\
\text { cannot be gathered) }\end{array}$ \\
\hline Characteristics licence & $\begin{array}{l}\text { Under exceptional circum- } \\
\text { stances }\end{array}$ \\
\hline Institution concerned & EMA \\
\hline
\end{tabular}

Marketing authorisation under exceptional circumstances is only granted if for the medicinal product concerned it is not expected to be possible to complete a full dossier, neither after marketing authorisation. Therefore general or conditional marketing authorisation is not possible. As intrinsically not all comprehensive data will be available upon granting the marketing authorisation such authorisation is granted subject to specific obligations. Such specific obligations may encompass the completion of certain studies, prescription and administration restrictions, and specific additional notification and product information obligations. ${ }^{63}$ Contrary to what is the case for conditional marketing authorisation, marketing authorisation under exceptional circumstances will normally not lead to general marketing authorisation, ${ }^{64}$ and continuation of the authorisation is dependent on an annual reassessment of fulfilment of the applicable conditions. ${ }^{65}$

\section{a. Legal Basis}

Article 14(8) of Regulation 726/2004 introduces the basis for the exceptional circumstances marketing authorisation. Annex I, Part II of Directive 2001/83 specifies the rules applicable. In addition, EMA issued a guideline for the granting of a marketing authorisation under exceptional circumstances. ${ }^{66}$

\section{b. Conditions}

The applicant needs to state objective, verifiable reasons why he is not able to provide comprehensive

58 Section 356(c) (1)(A) Title 21 U.S. Code

59 For further extensive guidance regarding this third requirement, please refer to the U.S. Expedited Programs Guidance.

60 U.S. Expedited Programs Guidance, 15.

61 Section 356 (c) (2) Title 21 U.S. Code.

62 FDA, 'Accelerated Approval Program', <https://www.fda.gov/ drugs/information-healthcare-professionals-drugs/accelerated -approval-program>, accessed on 9 October 2020.

63 Directive 2001/83, annex I, part II.6; Exceptional Circumstances Guideline, 2

64 Commission Regulation 507/2006, recital 6 .

65 Regulation 726/2004, art 14(8).

66 EMA, 15 December 2005, 'Guideline on procedures for the granting of a marketing authorisation under exceptional circumstances, pursuant to article 14(8) of Regulation (EC) No 726/2004 nr. EMEA/357981/2005, <https://www.ema.europa.eu/en/ documents/regulatory-procedural-guideline/guideline-procedures -granting-marketing-authorisation-under-exceptional -circumstances-pursuant/2004_en.pdf--gt- , accessed on 8 October 2020 (Exceptional Circumstances Guideline). 
data on the efficacy and safety of the medicinal products under normal conditions of use. ${ }^{67}$ Specifically, this is only accepted if comprehensive information or evidence cannot be gathered because (1) the indications for which the medicinal product is developed are encountered so rarely; (2) of the present state of scientific knowledge; or (3) it is contrary to general medical ethics to collect such comprehensive information. ${ }^{68}$ With regard to the latter option, the Exceptional Circumstances Guideline specifies that the relevant principles of medical ethics should be described, 'with precise reference to internationally accepted standards or other guidelines on ethics. The applicant should further justify the general acceptance of such principles and their applicability in this case. $^{.69}$

\section{c. US Animal Rule}

The EU exceptional circumstances procedure contains most similarities with the US 'Animal Rule'. Under the animal rule, marketing approval may be granted to certain new medicinal products based on 'adequate and well-controlled animal studies ${ }^{70}$ where 'definitive human efficacy studies cannot be conducted because it would be unethical to deliberately expose healthy human volunteers ${ }^{71}$ to the substance concerned. The FDA imposes restrictions to ensure safe use of the medicinal product where necessary, for example distribution restrictions or conditions, and the medicinal product's label must mention the animal rule applicability. ${ }^{72}$ As is the case for the EU exceptional circumstances procedure, the animal rule is only available if no other marketing authorisation procedure is available. Both procedures require on-going compliance of the applicant and im-

67 Regulation 726/2004, art 14(8).

68 Directive 2001/83, annex I, part II.6.

69 Exceptional circumstances Guideline, 5.

70 Section 314.610 Title 21 Code of Federal Regulations; for a more extensive overview of the requirements, see FDA, October 2015, 'Product Development Under the Animal Rule - Guidance for Industry', <https://www.fda.gov/media/88625/download>, accessed on 13 October 2020.

71 Section 314.600 Title 21 Code of Federal Regulations

72 Section 314.610(b)(2) and (3) Title 21 Code of Federal Regulations.

73 Section 314.610(b)(1) Title 21 Code of Federal Regulations.

74 Section 314.600 Title 21 Code of Federal Regulations.

75 Regulation 726/2004, art 83. pose strict transparency obligations regarding the exceptional nature of the authorisation towards potential patients. However, under the animal rule it is expected that over time ordinary marketing authorisation becomes available, following the conduct by the authorisation holder of (mandatory) post marketing studies. ${ }^{73}$ This intrinsically never is the intention of the EU exceptional circumstances procedure. In addition, the scope of the animal rule applicability is limited to specific types of medicinal products, focussing on the prevention of 'serious or life-threatening conditions caused by exposure to lethal or permanently disabling toxic biological, chemical, radiological, or nuclear substances. ${ }^{74}$

\section{CHMP Opinion on Compassionate Use}

\begin{tabular}{|l|l|}
\hline Name tool/procedure & $\begin{array}{l}\text { CHMP opinion on compas- } \\
\text { sionate use }\end{array}$ \\
\hline Legal basis & $\begin{array}{l}\text { Recital 33 and art. 83 Regu- } \\
\text { lation 726/2004 }\end{array}$ \\
\hline Date of introduction & 2004 \\
\hline $\begin{array}{l}\text { Conditions for use/access } \\
\text { (1) Unmet need? }\end{array}$ & $\begin{array}{l}\text { (1) De facto yes: 'cannot be } \\
\text { treated satisfactorily by an } \\
\text { authorised medicinal prod- } \\
\text { uct' } \\
(\mathbf{2}) \text { targeting a chronically } \\
\text { or seriously debilitating or } \\
\text { life-threatening disease; no } \\
\text { satisfactory alternative; un- } \\
\text { dergoing clinical trial }\end{array}$ \\
\hline $\begin{array}{l}\text { Characteristics licence } \\
\text { Institution concerned }\end{array}$ & No licence \\
\hline
\end{tabular}

The aim of the compassionate use scheme is to make unauthorised medicinal products still in development available to patients under strict conditions. In 2004, a legal framework was introduced for member states to allow compassionate use for medicinal products eligible for centralised marketing authorisation. ${ }^{75}$ Important to note is that even though medicinal products eligible for centralised authorisation are concerned, the power to grant compassionate use remains with the member states. A second important nuance is that via this procedure no marketing au- 
thorisation is obtained, only the use of the medicinal product is enabled. If a member state uses this procedure for medicinal products falling within the scope of the centralised marketing authorisation procedure, it must notify EMA thereof. ${ }^{76}$ Regarding medicinal products for which the centralised marketing authorisation procedure is optional, this notification requirement is only upheld when CHMP has already confirmed eligibility for the centralised procedure. ${ }^{77}$ Following such notification, CHMP may adopt an opinion on the conditions for use of the medicinal product, the conditions for distribution thereof, and the patients targeted. Member States are not required to follow such opinions, but 'take account of any available options. ${ }^{, 78}$

\section{a. Legal Basis}

Regulation 726/2004 introduces the concept of compassionate use. In addition, EMA has issued a Compassionate Use Guideline. $^{79}$

\section{b. Conditions}

The conditions for granting compassionate use are reflected in the definition of compassionate use in Regulation 726/2004. First, the compassionate use procedure reflected in Regulation 726/2004 only concerns medicinal products which fall within the scope of centralised marketing authorisation. Compassionate use for medicinal products with decentralised marketing authorisation exists, though is out of scope for the procedure described in Regulation 726/2004. Second, the target group of patients suffers from a chronically or seriously debilitating disease or a disease considered to be life-threatening. Third, no authorised medicinal product provides a satisfactory treatment. Fourth, the medicinal product for which compassionate use is requested is already subject to a marketing authorisation application, or is undergoing clinical trials. ${ }^{80}$

\section{c. US Expanded Access}

The FDA describes expanded access as 'a potential pathway for a patient with an immediately life-threatening condition or serious disease or condition to gain access to an investigational medical product [...] for treatment outside of clinical trials where no comparable or satisfactory alternative therapy options are available. $^{81}$ (emphasis added). Three types of expanded access exist: for individual patients, for intermediate-size patient populations, and for larger patient populations. ${ }^{82}$ Here, focus will be on the general conditions applicable to all such patient populations. As the definition already indicates, three criteria should be fulfilled in order to be able to benefit from expanded access: (1) the patient (group) has a serious or immediately life-threatening disease for which no satisfactory alternative therapy exists; (2) the potential benefit justifies the potential risks of the treatment use, also in light of the context of the disease to be treated; and (3) the requested treatment will not interfere with clinical investigations supporting market access. ${ }^{83}$ Apart from the fact that in the US the procedure is centralised, while at EU level compassionate use is a member state competence, the procedures are very similar: both procedures do not grant marketing authorisation and consider both the severity of the disease and whether alternatives for treatment exist.

\section{Adaptive Pathways}

Adaptive pathways was introduced as a pilot project by EMA in 2014. ${ }^{84}$ The aim of adaptive pathways is to 'balance timely access for patients who are likely to benefit most from the medicine with the need to provide adequate evolving information on the benefits and risks of the medicine itself ${ }^{\prime}{ }^{85}$ After the adap-

\footnotetext{
6 ibid art 83.3.

7 Compassionate Use Guideline, 5.

78 Regulation 726/2004, art 83.5.

79 EMA, 19 July 2007, 'Guideline on compassionate use of medicinal products, pursuant to article 83 of regulation (EC) No 726/2004' nr. EMEA/27170/2006, <https://www.ema.europa.eu/ en/documents/regulatory-procedural-guideline/guideline -compassionate-use-medicinal-products-pursuant-article-83 -regulation-ec-no-726/2004_en.pdf> accessed on 8 October 2020 (Compassionate Use Guideline).

80 Regulation 726/2004, art 83.2.

81 FDA, 'Expanded Access', <https://www.fda.gov/news-events/ public-health-focus/expanded-access $>$ accessed on 13 October 2020.

82 Sections 312.300 to 312.320 Title 21 Code of Federal Regulations; FDA, June 2016, 'Expanded Access to Investigational Drugs for Treatment Use - Questions and Answers - Guidance for Industry', <https://www.fda.gov/media/85675/download>, accessed on 13 October 2020, 2.

83 Section 312.305(a) Title 21 Code of Federal Regulations

84 Final Adaptive Pathways Report, 1.

85 Final Adaptive Pathways Report, 1.
} 
tive pathways pilot was closed in 2016, adaptive pathways continued to exist within the framework of parallel consultation of EMA and HTA bodies. ${ }^{86}$ If accepted, additional support is offered to the applicant in the format of an additional pre-submission meeting to the one already foreseen in the parallel advice procedure, during which it is explored what is the most appropriate development route for the medicinal product at issue. ${ }^{87}$

\begin{tabular}{|l|l|}
\hline Name tool/procedure & $\begin{array}{l}\text { 'Adaptive pathways' or } \\
\text { 'MAPPS' (Medicines Adap- } \\
\text { tive Pathways to Patients), } \\
\text { previously 'adaptive licens- } \\
\text { ing' }\end{array}$ \\
\hline Legal basis & N/A \\
\hline Date of introduction & 2014 \\
\hline $\begin{array}{l}\text { Conditions for use/access } \\
\text { (1) Unmet need? } \\
\text { (2) Other }\end{array}$ & $\begin{array}{l}\text { (1) Generally yes (including } \\
\text { potential future need) } \\
(\mathbf{2}) \text { iterative development } \\
\text { plan; involvement stake- } \\
\text { holders; real world evi- } \\
\text { dence }\end{array}$ \\
\hline Characteristics licence & Permanent or conditional \\
\hline Institution concerned & EMA \\
\hline
\end{tabular}

\section{a. Legal Basis}

Like PRIME, the adaptive pathways scheme is a tool aiming to boost certain of the previously discussed existing legal tools, without introducing a new legal

86 For more information, see II.2; Adaptive Pathways Guidance, 1.

87 Adaptive Pathways Guidance, 6.

88 EMA, 1 August 2016, 'Guidance for companies considering the adaptive pathways approach' nr. EMA/527726/2016 <https:// www.ema.europa.eu/en/documents/regulatory-procedural -guideline/guidance-companies-considering-adaptive-pathways -approach_en.pdf> , accessed 8 October 2020 (Adaptive Pathways Guidance).

89 EMA, 28 July 2016, 'Final report on the adaptive pathways pilot', <https://www.ema.europa.eu/en/documents/report/final -report-adaptive-pathways-pilot_en.pdf $>$ accessed on 8 October 2020 (Final Adaptive Pathways Report).

90 Adaptive Pathways Guidance, 1; Final Adaptive Pathways Report, 8.

91 Final Adaptive Pathways Report, 2.

92 ibid 9 basis. The most comprehensive reflection of the concept and rules applicable under adaptive pathways can be found in the EMA documents referred to in this paper as the Adaptive Pathways Guidance ${ }^{88}$ and the Final Adaptive Pathways Report. ${ }^{89}$ Both documents state that 'the same criteria/principles and legal tools will apply as for any other new medicine. ${ }^{90}$ This must be interpreted as meaning that for each legal tool deployed, the specific conditions for that legal tool must still be met for the medicinal product concerned, in addition to the adaptive pathways conditions as discussed below. Depending on which legal tools the specific adaptive pathways approach embraces, the legal basis should change accordingly.

\section{b. Conditions}

A medicinal product is eligible for adaptive pathways if it fulfils three specific criteria. First, an iterative development plan can be introduced, prospectively planned. This implies that evidence can be gathered step-wise, whereby either the categories of recipients are expanded gradually or whereby remaining uncertainty regarding the medicinal product is progressively reduced by collecting additional data after the initial marketing authorisation has taken place. Second, involvement of HTA bodies and other downstream stakeholders such as patients should be ensured, the applicant's proposal including suggestions on how the demands of such stakeholders can be met. In that regard, the applicant should present a strategic plan regarding how to involve relevant stakeholders early onwards throughout the development of the medicinal product. Third, real-world data must complement randomised clinical trials. In its proposal the applicant must set out how it will collect real world evidence to further refine the benefit/risk profile and therapeutic value of the medicinal product. ${ }^{91}$ In addition to these three criteria, the Final Adaptive Pathways Report stresses that the procedure is only available to medicinal products which are likely to offer a solution to an unmet medical need. The document nuances that in the context of adaptive pathways, this term should be understood broadly, 'including potential future need'. ${ }^{2}$ The document also notes that certain applications for adaptive pathways during the pilot have indeed been rejected since they did not display an unmet need. Strangely enough, the Adaptive Pathways Guidance, a document also issued by EMA only four days after the Final Adaptive Path- 
ways Report, provides a different insight on the concept of 'unmet need'. After initially confirming in the introduction that adaptive pathways is only available for medicinal products focussed on providing a solution for an unmet medical need, the Adaptive Pathways Guidance surprisingly adds that the applicant's proposal should include a value proposition strategy which has to identify

'how the product can add value compared to existing options, for example, by addressing an unmet need or high healthcare burden. [...] Reduction in health care resource use is a valid part of a value proposition and the approach to demonstrate expected savings through the use of the intervention may be discussed. ${ }^{93}$ (Emphasis added)

On the basis of this statement, it can only be concluded that value propositions other than based on an unmet need are also available to legitimise the use of adaptive pathways, despite the fact that this option is not discussed elsewhere and despite the fact that other documentation regarding adaptive pathways seems to focus solely on the requirement of an unmet need. The introduction of the concept of value proposition demonstrates even more what is highlighted higher: the adaptive pathways criteria should be combined with the criteria in place for the legal tools used in that specific adaptive pathways scheme, and cannot replace them. A different view would entirely erode the safeguards put in place for such legal tools via their specific eligibility criteria. Most of the available legal tools are based on the concept of 'unmet need' and no matter how this concept is defined, it can definitely not be assimilated with the demonstration of a value proposition. Another opinion would therefore be contradictory to the claim that ' a]s for any medicine, a marketing authorisation will only be granted if the balance of benefits and risks for a defined patient population is found to be positive' (emphasis added). ${ }^{94}$

\section{c. US Procedure?}

The characteristics of adaptive pathways are specific, and therefore no truly aligned procedure can be found at US level. This does not mean that the use of real world data or real world evidence is not encouraged in the US. On the contrary, the use of real world evidence is embedded in US legislation, ${ }^{95}$ and the FDA has issued considerable guidance setting out when and how real world data can be used, mostly in a post-market setting. ${ }^{96}$ However, contrary to the EU approach, such guidance in relation to the use of real world data is not procedure-specific. As no specific US procedure focusses on real world data as a requirement to accelerate access to medicinal products, adaptive pathways will here be compared to the breakthrough therapy designation. Most authors validly perceive breakthrough therapy designation as the US alternative to PRIME, a claim strengthened by the fact that EMA and the FDA exchange information in the context of these programs. Specifically, they 'track submitted requests for PRIME and breakthrough therapy designation and compare final review outcomes, including specific reasons for a designation request denial. ${ }^{97}$ However, displaying this procedure here better reflects the correlation with the other US procedures, even though breakthrough therapy indeed lacks certain pivotal characteristics to be truly comparable to adaptive pathways as will be highlighted below. The aim of breakthrough therapy is to expedite the development and review of a medicinal product. ${ }^{98}$ In order to be eligible for breakthrough therapy, two conditions need to be fulfilled. First, the medicinal product is aimed to treat a serious or life-threatening disease or condition. Second, preliminary clinical evidence exists indicating that the medicinal product may demonstrate substantial improvement over existing therapies on one or more clinically significant endpoints. ${ }^{99}$ The terminology 'substantial improvement' is explained as 'a clear advantage over available therapy', and a 'clinical significant endpoint' should be interpreted as 'an effect on irreversible morbidity or mortality (IMM) or on symptoms that represent serious consequences of the disease, ${ }^{100}$ for example substantial treatment effects observed early in clinical development. Gener-

\footnotetext{
93 Adaptive Pathways Guidance, 4.

94 Final Adaptive Pathways Report, 8.

95 Section $355 \mathrm{~g}$ U.S. Code.

96 See for example: FDA, May 2019, 'Submitting Documents Using Real-Word Data and Real-World Evidence to FDA for Drugs and Biologics', <https://www.fda.gov/media/124795/download> accessed on 16 October 2020; FDA, January 2019, 'Sentinel System - Five-year strategy 2019-2023' <https://www.fda.gov/media/ $120333 /$ download $>$ accessed on 16 October 2020.

97 PRIME Guidance, 10.

98 Section 356(a)(1) Title 21 U.S. Code.

99 ibid

100 U.S. Expedited Programs Guidance, 12
} 
ally, this would correspond to a phase 1 or 2 clinical trial, a requirement which clearly contrasts with fast track designation, where nonclinical evidence may suffice. ${ }^{101}$ Breakthrough therapy conveys all of the fast track designation features, ${ }^{102}$ and in exchange for more robust evidence, includes more profound advantages. Specifically the advantages of breakthrough therapy for the applicant may include (1) meetings with the review team throughout the development of the medicinal product; (2) receipt of advice regarding the medicinal product development, to ensure the development program gathering nonclinical and clinical data necessary for approval is as efficient as practicable; (3) involvement of senior managers and experienced review staff for a collaborative cross-disciplinary review; (4) assignment of a project lead for the FDA review team as scientific point of contact; and (5) ensuring the design of the clinical trial is as efficient as practicable. Both breakthrough therapy and adaptive pathways are focussed on enhanced interaction with the competent regulatory authority and take into account whether an unmet medical need is present. Also both procedures are built on other pre-existing legal tools. However, the specific characteristics of adaptive pathways (iterative development plan, involvement of stakeholders and use of real world data) are not reflected in breakthrough therapy.

\section{Covid-19 Potential}

Many of the abovementioned EU procedures accelerating access to medicinal products may have the potential to assist in the expedited access to a Covid-19 vaccine. This counts for as well accelerated assessment, parallel consultation of EMA and EUnetHTA, PRIME and conditional marketing authorisation. Whether the concept of 'unmet need' is interpreted broadly or more restrictively, an effective Covid-19 vaccine will most likely meet the threshold. In addition, further potential procedures which were out of scope of the above assessment may hold great potential for Covid-19 vaccines. In the first place, reference should of course be made to shortened approval procedures for a new use of existing medici-

101 ibid 11.

102 FDA FAQ Breakthrough Therapies. nal products. However, potentially also procedures expediting access to specific types of medicinal products could provide further solutions.

\section{Conclusion: EU v. US Approach}

The overview of procedures accelerating centralised authorisation for medicinal products demonstrates that many of the existing EU procedures are related or intertwined. Applicants should cautiously scrutinise the available options in order to decide which procedure can most easily accelerate market access to their products. This is demonstrated in the abovementioned Covid-19 example. When a comparison with available US procedures is made, it can be concluded that even though the procedures are not oneon-one copies, many procedures have a counterpart in the US

For most of the EU procedures, the applicant has to demonstrate that the medicinal product concerned remedies an unmet (medical) need. However, the way this criterion is to be understood varies from procedure to procedure, which does not add to the legal certainty of the applicants. Even though each procedure targets a different situation, it is to be questioned whether it would not be more practical for all parties to have one clear coherent understanding of this terminology. After all, the various procedures still require other criteria to be fulfilled, which could reflect the nuances specific to the procedures concerned. The US Expedited Programs Guidance gives applicants guidance on the concepts of what constitutes 'unmet medical need', independently of the applicable procedure. Even though it is of a non-binding nature, EU policy makers could consider drawing inspiration from such clarity. However, independently of how this EU criterion of unmet need is defined per procedure, it is clear that this criterion cannot be assimilated with the mere proof of a 'value proposition'. Therefore, it can only be concluded that the criteria in place for adaptive pathways are cumulative to those of the other legal tools, and cannot simply replace them. The opposite point of view would erode the criteria safeguarding such legal tools.

From a historical perspective the introduction of the various EU procedures may have accorded to the needs of the market at such times, however it can only be concluded that the end result is chaotic, incoherent and unnecessarily complicated. The regula- 
tors seem aware of this, no longer trying to add new legal procedures but bundling the existing procedures in new 'tools'. Unfortunately, this mostly seems to add an additional layer of complexity to the al- ready dispersed landscape of early market access. The existing US procedures, each enjoying their own legal basis, can more easily be unravelled by interested applicants than their EU counterparts. 